\title{
Effect of Masking of Imagery with Picture-Stimuli on the Memory of Students of Architecture and Humanities. \\ Suchitra Roy Chowdhury
}

\begin{abstract}
The current study investigates the effect of masking of mental images with congruent and incongruent picture-stimuli among the students of Architecture and Humanities. Students from these two streams were chosen $(N=60$, mean age $=19$ yrs. $)$. Participants were shown a list of concrete words and were urged to make mental images. The images made by the participants were covered by the Experimenter by the congruent and incongruent pictures. The effect of masking was compared among the high and low imagery usage participants. Two t tests were computed to understand the significant differences between the means. A non-significant t of 1.031 was obtained for the high imagery expert group while, a significant $t$ of $4.699, p<0.001$ with $\mathrm{df} \mathbf{5 8}$ was seen for low imagery expert group. Additionally, a two-way ANOVA was computed followed by Tukey's post-hoc test to understand the difference in the overall recognition scores between the high and low imagery usage groups, the effect of masking on memory, and the interaction effect of both the variables. The findings have been discussed and interpreted with limitations and suggestions.
\end{abstract}

Key words: Congruent Pictures, Incongruent pictures, Imagery, Masking, and Picture-like Phenomenon.

\section{INTRODUCTION}

According to Cicero (1966) the Art of Memory was believed to have been originated by a poet Simonides. Simonides could recognize the remains of the guests after the roof had caved in according to their seating arrangements. Numerous studies have expansively explored different aspects of imagery like, Paivio (1991) on dual-coding theory, Shephard, and Metzler (1988) on mental rotation, Kosslyn, Ball, and Reiser (1978) on imaginal scanning, Cooper, (1975) on mental rotation of two-dimensional shapes. Pictures in general are superior than verbal labels in helping one remember the information. Snodgrass's (1984) Hybrid model suggest that the perceptual information coming from the environment is generally matched with the stored prototypical images. When the stimuli is in form of pictures the mismatch between the perceived data and the internal prototypical representation is greater which results in extensive processing and subsequent better memory for pictures.

Revised Manuscript Received on November 05, 2019.

* Correspondence Author

Suchitra Roy Chowdhury*, Assistant Professor, Department of Psychology, Mithibai College of Arts Chauhan Institute Of Science And Amrutben Jivanlal College Of Commerce And Economics, Mumbai (Maharashtra), India. E-mail: suchitraroyc@gmail.com

(c) The Authors. Published by Blue Eyes Intelligence Engineering and Sciences Publication (BEIESP). This is an open access article under the CC BY-NC-ND license (http://creativecommons.org/licenses/by-nc-nd/4.0/)
Pictorial stimuli entails a superior sensory code, the semantic representation and the corresponding labels may be identical for pictures (Nelson et al., 1976). However, the nature of objects sometimes would determine whether creation of imagery would be easier or difficult. For instance, Paivio (1975) argued that concrete words as against the abstract words facilitate both verbal and nonverbal codes. This presence of two codes for pictures against only one verbal code for words promotes enhanced memory for pictures. In another study, Kahlaoui et al. (2007) reported longer RTs and more errors in imaging biological objects than the man-made objects. Biological objects are structurally similar, but man-made objects are structurally dissimilar. The sensorimotor experiences and the understanding the functions and actions of man-made objects are very important. Therefore, identifying biological objects are difficult as opposed to man-made objects. At other times, the type of retrieval would determine the superiority of pictures or words. Like, Weldon et al. (1987) demonstrated that pictures show better memory on the explicit free recall test that involves conceptually driven processing while, words show a superior memory if they are tested as implicit fragment completion test which involves data driven processing. The study supports the transfer appropriate processing view. Morris and Franks (1977) when manipulated the levels of processing as a function of recognition test found that words originally learned as rhymes when tested by rhyme recognition test had stronger memory traces in comparison to semantic acquisition condition. In other words, memory is not just contingent upon the level of processing but also on the match between the encoding and retrieval phases. Closer the match between learning context, mood or state, better the memory. Like, Godden and Baddeley (1975) found that words learnt underwater was also recalled better underwater while words learnt on land was recalled better on land. Sternberg et al.'s (1991) findings however denoted that picture-superiority effect can challenge the study-test congruence effect. In their study, they found that hit rates for PW (Picture-Word) category were higher than WW (Word-Word category).

A striking reason in establishing picture-superiority effect is also the individual differences in the ability in generating and manipulating images. Palmiero et al., (2015) indicated that people who scored high on creativity tasks were also high on image transformation imagery ability. Garderen (2006) revealed that gifted students as compared to students with learning disability, and average- achieving students performed better on spatial visualization measures.

Published By:

Blue Eyes Intelligence Engineering

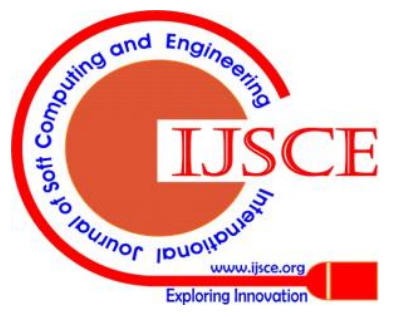




\section{Effect of Masking of Imagery with Picture-Stimuli on the Memory of Students of Architecture and Humanities.}

The study also emphasized the role of task at hand in evoking differing imageries. The researcher found that performance on mathematical word problem solving was positively correlated with use of visual images while, performance on spatial visualization measures was positively correlated with use of schematic imagery. Potter and Merwe (2001) opined that the academic performance in Engineering students was influenced by the spatial ability and ability to use mental imagery. Quealey (1980) demonstrated that students from academic courses that demands high spatial ability i.e. Architecture, were better able not just to experience imagery but also manipulate imagery as compared to students from academic courses that demands less spatial ability i.e. Humanities. Spatial imagery by itself is not a single faculty. It involves visualizing spatial location and transforming location (Thompson et al., 2009). Individuals who are trained to make mental images possess both object visualization ability i.e., processing in terms of high-resolution pictorial features of objects and, spatial visualization ability i.e., mentally transforming objects and processing the space relations between the objects ( Kozhevnikov et al., 2005). The current study however intends to determine whether skill in using imagery outperforms the imagery as picture-like phenomenon. In other words, the study examines whether masking of imagery with incongruent and congruent pictures for high imagery usage group (students from Architecture) have any effect on their memory, in contrast to masking of imagery with incongruent and congruent pictures for low imagery usage group (students from Humanities).

\section{HYPOTHESES}

1. Masking of imagery by pictures does not affect memory of students of Architecture i.e., There is no difference in the mean recognition scores when imagery is masked by incongruent pictures than when it is masked by congruent pictures for the students of Architecture.

2. Masking of imagery by pictures affect memory of students of Humanities i.e.,

The mean recognition scores of words that is masked by congruent pictures will be more than when the words are masked by incongruent pictures for the students of Humanities.

\section{DESIGN:}

\section{$2 \times 2$ mixed design}

Independent Variables

$I_{1}$ : Usage of imagery (High Versus Low). Students of Architecture whose subject of study demand extensive usage of imagery were operationally defined as HIGH level group while students of Humanities whose subject of study demand less usage of imagery were operationally defined as LOW level group.
$\mathrm{IV}_{2}$ : Congruency of pictures (Congruent versus incongruent). Congruent pictures are the ones wherein the word shown to the $\mathrm{P}$ for which $\mathrm{P}$ had to make a corresponding imagery and the picture shown by the $\mathrm{E}$ matched with each other. Incongruent pictures are the ones wherein the word shown to the $\mathrm{P}$ for which $\mathrm{P}$ had to make a corresponding imagery and the picture shown by the $\mathrm{E}$ did not match with each other. Both the levels were given to both the groups i.e. repeated measures IV.

Dependent Variable: Mean number of words correctly identified by the Participants.

\section{IV.METHOD:}

Experimental method. Sample: N=60 (EG-1=30, EG-2=30), Mean age of the participants $=19$ yrs. For high level of usage of imagery condition students from Architecture were selected while, for low level of usage of imagery condition students from Humanities were selected.

Tools:

- A pair of demo words and pictures for congruent and incongruent conditions. These were not repeated in the main experiment.

- A set of 30 concrete words.

- A set of 30 pictures, 15 congruent and 15 incongruent presented randomly.

- Recognition sheet with original 30 words and additional 45 new words.

- Stationery

- Stop watch

- Metronome

Procedure:

Rapport was established with the participants. Participants were shown the words one at a time over the screen for 1 second. Immediately after 1 second, participants were shown the blank white screen and were urged to make a mental image of the word shown for 5 seconds. The procedure continued for all 30 cards, each time the word would be followed by the blank screen. Words presented to the participants were nouns from the standardized list that were equated by Snodgrass and Vanderwart,1985 on the measures of familiarity, frequency of occurrence, age of acquisition, concreteness, imagery, meaningfulness, and emotionality. Pictures shown were line drawings that represented the specific concept from the standardized list of Snodgrass and Vanderwart, 1985.

After 30 trials, participants were given the recognition sheet to circle the words that they think they had seen earlier in the experiment. They were given 5 minutes for the task. Participants were debriefed and escorted outside the laboratory. 


\section{V.RESULTS}

The data were checked for normal distribution. No outliers were observed. Mean recognition score were calculated for all four conditions i.e., High Incongruent, High Congruent, Low Incongruent, and Low Congruent. Two t tests were computed to analyse the data. An additional $\mathrm{F}$ test was calculated to understand the main effect and the interaction effects.

Table 1: Descriptive data, mean, SD and t calculation of

\begin{tabular}{|l|l|l|}
\hline \multicolumn{1}{|c|}{ high imagery group $(\mathrm{N}=\mathbf{3 0})$} \\
\hline & $\begin{array}{l}\text { Congruent } \\
\text { condition }\end{array}$ & $\begin{array}{l}\text { Incongruent } \\
\text { condition }\end{array}$ \\
\hline Mean & 11.767 & 11.000 \\
\hline SD & 2.788 & 2.971 \\
\hline \multicolumn{3}{|c}{$\mathbf{t}_{(58)}=\mathbf{1 . 0 3 1 , n . s .}$} \\
\hline
\end{tabular}

Table 2: Descriptive data, mean, SD and t calculation of low imagery group $(\mathrm{N}=30)$

\begin{tabular}{|l|l|l|}
\hline & $\begin{array}{l}\text { Congruent } \\
\text { condition }\end{array}$ & $\begin{array}{l}\text { Incongruent } \\
\text { condition }\end{array}$ \\
\hline Mean & 11.433 & 7.200 \\
\hline SD & 4.183 & 2.619 \\
\hline \multicolumn{3}{|c|}{$\mathbf{t}_{(58)}=\mathbf{4 . 6 9 9}, \mathbf{p}<0.001$} \\
\hline
\end{tabular}

Table3: Comparison of mean scores of the groups with $F$ values

\begin{tabular}{|l|l|l|}
\hline & $\begin{array}{l}\text { High Imagery } \\
\text { condition } \\
\text { (N=30) }\end{array}$ & $\begin{array}{l}\text { Low Imagery } \\
\text { condition(N=30) }\end{array}$ \\
\hline $\begin{array}{l}\text { Congruent } \\
\text { pictures }\end{array}$ & 11.767 & 11.433 \\
\hline $\begin{array}{l}\text { Incongruent } \\
\text { pictures }\end{array}$ & 11.000 & 7.200 \\
\hline
\end{tabular}

$F(3,116)=13.212, p<0.05$

$F(3,116)=1255.66, p<0.05$

$F(1,116)=13.522, p<0.05$

\section{DISCUSSION}

Hypothesis 1 states that masking of imagery by pictures does not affect memory of students of Architecture i.e., There is no difference in the mean recognition scores when imagery is masked by incongruent pictures than when it is masked by congruent pictures for the students of Architecture. Rademaker and Pearson (2012) suggest that with practice individuals can have better metacognitive insights into their own imagery. They introspect on the vividness, details and accuracy of the mental image generated by them. Low confidence in the construction of image may propel people to reconsider their subjective experience to make it more closer to reality. Bilda (2006) asserted that Architecture students who were better at imaging situations were also better at developing their ideas and had satisfying designing solutions. Potter and Merwe's (2001) findings indicated that the academic performance of students of Engineering was influenced by their spatial ability and ability to create visual imagery. Further, these abilities can be enhanced through appropriate training. Blazhenkova and Kozhevnikov (2009) proposed a threedimensional model of cognitive style comprising of visual, verbal and spatial components. Imagery consist of two systems viz "object imagery" and "spatial imagery". While the former helps in processing the structural qualities like shape, colour etc.... of the objects, the latter helps in mentally transforming the objects, understanding the relation between the parts, or part and the whole and so on.

Students who are related to visual art forms like architecture may have greater ability in either or both forms of imageries. This probably give them an edge over the others in mentally manipulating objects. Hence, the current study predicted that nature of picture i.e., congruent or incongruent will have no effect on the recognition. The expertise or training that architecture students receive will help in challenging the "image as picture" metaphor. A nonsignificant $t$ value of 1.031 with df 58 failed to reject the null hypothesis. In other words, the nature of masking did not impact the memory of students of architecture.

Hypothesis 2 states that masking of imagery by incongruent pictures affect memory of students of Humanities i.e., the mean recognition scores of words that is masked by congruent pictures will be more than when the words are masked by incongruent pictures for the students of Humanities. Visual imagery share qualities with pictures. Finke (1989) argue that imagery is characterized by five principles viz, implicit encoding, perceptual equivalence, spatial equivalence, transformational equivalence, and structural equivalence. All of these funnel into one unique quality of imagery i.e., it is like actual perception. Similar mechanisms in visual system get triggered off when one make mental images and when one encounters the visual data in the environment. Borst et al. (2008) found that participants when scanned over pattern of dots during perception in their iconic image i.e., images of just-seen pattern and images created from information stored in long term memory, the scanning rates in perceptual tasks correlated with the scanning rates in imagery tasks. The findings supported the evidence that mental images and the percept are represented similarly.

Published By:

Blue Eyes Intelligence Engineering

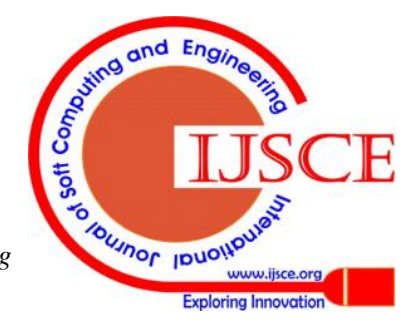




\section{Effect of Masking of Imagery with Picture-Stimuli on the Memory of Students of Architecture and Humanities.}

Brooks (1968) demonstrated that participants reported lesser RTs when the two simultaneous tasks involved different modalities, one pictorial and the other verbal. Participants' mentally visualizing capital " $F$ " did not deter their verbal responses of "Yes/No" as one task was visual in nature while the other verbal. Kosslyn and Shwartz (1977) construed images as quasi-pictorial surface representation. Perky (1910) reported that when participants were asked to imagine stimulus like a "tomato" on a blank screen they found it very difficult to differentiate between their imagined object and the faint picture of the object presented by the Experimenter. Perky suggested that a supraliminal visual perception when distinct is mistaken for imagination though the stimuli is actually presented externally by the Experimenter. The image of imagination share similarities with the everyday perception. Hence, in the current experiment when participants were asked to make images their visual images that had picture-like quality got affirmed when congruent pictures are shown to them by the Experimenter. For the congruent picture condition, the internal pictorial representation created by the participants matched with the prototypical image shown by the Experimenter. The picture stimuli therefore did not hinder the image made by the participants. Hence, participants were more likely to remember the words for which the imagery constructed was followed by congruent pictures. In contrast, when incongruent pictures were presented by the Experimenter the mental image made by the participant got masked. The internal pictorial representation created by the participant did not match with the external incompatible representation given by the Experimenter. A significant $t$ value of 4.699 with $\mathrm{df} 58$ confirmed that the nature of masking did have an impact on the memory of students of Humanities. A significant $F$ value of 13.212 with df $(1,116)$ indicated that the overall recognition scores of high imagery usage group was more than that of the low imagery usage group. This again support the finding that the nature of masking did not influence the memory of the students from Architecture. Their ability to deal with images outsmarted the pictorial quality of images. In other words, people who are skilled with the usage of images do not get influenced by their images getting covered by pictures especially the incongruent ones. But the recognition scores of low imagery usage group suffered as incongruent pictures hindered the images created by them. A significant $F$ value of 125.66, with df $(1,116)$ indicated that overall there was a significant difference in the recognition scores of congruent and incongruent picture stimuli. The third significant $F$ value of 13.522 indicated the interaction effect of the two variables. Tukey's post-hoc test denoted that there exist a significant difference between all the four means i.e., high usage incongruent group, high usage congruent group, low usage incongruent group, and low usage congruent group.

\section{VII.CONCLUSION}

The current study affirms the "imagery as picture-like" in case of students of Humanities, but not for the students of Architecture. The study hence concludes that expertise in imagery can challenge the "image as pictorial description" assertion. Limitations and Suggestions: The current study involved only Architecture students. Further investigation can include students from other subjects like mathematics, physics, interior designing and so on. Further, the results obtained from the current study cannot be generalized to other age groups. Future investigations can incorporate people from varying age groups. The other demographic details like the socio-economic status, education of the parents, occupation of the parents and so on can also be explored. No measures were taken in the current study to equate the imagery abilities of the students. It is possible that some of the low imagery usage group participants may be involved in drawing, sketching, dancing etc.... that may influence their performance on the memory task. Future studies can have a better representative sample in this context.

\section{REFERENCES:}

1. Bilda,Z. (2006). The Role of Mental Imagery in Conceptual Designing. Electronic thesis.

2. Retrieved from http://www.core.ac.uk on 26/4/19.

3. Blazhenkova,O. and Kozhevnikov,M (2009). The New ObjectSpatial_Verbal Cognitive Style Model: Theory and Measurement. Applied Cognitive Psychology, 23,638-663.

4. Retrieved from http://www.proquest.com on 25/4/19.

5. Borst, G. and Kosslyn,S.M.(2008). Visual Mental Imagery and Visual Perception: Structural equivalence revealed by scanning processes. Memory and Cognition, 36(4), 849-862. doi: 10.3758/MC.36.4.849.

6. Retrieved from http://www.kosslyn_visualmentalimagery.pdf on 14/12/18.

7. Brooks, L. (1968). Spatial and Verbal Components of the Act of Recall. Canadian

8. Journal of Psychology, 22(5), 349-36.

9. Retrieved from http:// www.researchgate.net on 12/4/19.

10. Cicero De Oratore, II, LXXXVI. Quoted in F.A. Yates (1966) The Art of Memory. London: Routledge and Kegan Paul.

11. Retrieved from http:// www.thebrain.mcgill.ca.pdf on 19/4/19.

12. Cooper, L.(1975). Mental Rotation of Random Two-dimensional Shapes. Cognitive Psychology, 7(1), 20-43.

13. Retrieved from http:// www.sciencedirect.com on 12/4/19.

14. Finke, R.A. (1989). Principles of Mental Imagery. American Journal of Psychology,104(3).

15. Retrieved from http:// www.researchgate.net on 25/4/19.

16. Garderen, D.V. (2006). Spatial Visualization, Visual Imagery, and Mathematical Problem-Solving of Students with Varying Abilities. Journal of Learning Disabilities, 39(6), 496-506.

17. Retrieved from http:// www.ideal-group.org on 24/4/19.

18. Godden, D.R. and Baddeley, A.D. (1975). Context-Dependent Memory in Two Natural Environments: On Land and Underwater. British Journal of Psychology. 66(3).

19. Retrieved from http://www.onlinelibrary.wiley.com on 24/4/19.

20. Kahlaoui,K., Baccino, T.and Mannie, M.(2007). Pictures and Words: Priming and Category Effects in Object Processing. Current Psychology Letters: Behaviour, Brain and, Cognition,3(23).

21. Retrieved from http:// www. journals.openedition.org on 24/4/19

22. Kosslyn, S.M., Ball, T.M., and Reiser, B.J. (1978). Visual Images Preserve Metric Spatial Information: Evidence from Studies of Image Scanning. Journal of Experimental Psychology: Human Perception and Performance, 4(1), 47-60.

23. Retrieved from http://www.proquest.com on 12/10/18.

24. Kosslyn, S. and and Shwartz, S. (1977). A Simulation of Visual Imagery. Cognitive Science,1, 265-295.

25. Retrieved from http://www.onlinelibrary.wiley.com on 26/4/19.

26. Kozhevnikov,M., Kosslyn,S., and Shephard,S. (2005). Object-SpatialVerbal Cognitive Style Model. Electronic data.

27. Retrieved from http:// www. nmr.mgh.harvard.edu on 25/4/19

28. Morris, C.D. and Franks, J.J. 91977). Levels of Processing versus Transfer Appropriate Processing. Journal of Verbal Learning and Verbal Behaviour, 16(5), 519-533.

Blue Eyes Intelligence Engineering \& Sciences Publication 
29. Retrieved from http:// www. sciencedirect.com on 24/4/19.

30. Nelson, D.L. Reed, V.S. and Walling, J.R. (1976). Pictorial Superiority Effect. Journal of Experimental Psychology: Human Learning and Memory, 2(5), 523-528.

31. Retrieved from http://www.researchgate.net on 13/4/19.

32. Paivio,A. and Clark, J. (1991). Dual Coding Theory and Education. Educational Psychology Review, 1-19.

33. Retrieved from http://www.researchgate.net on 13/4/19.

34. Palmiero,M., Nori, R., aloisi, V., Ferrara<M. and Piccardi, L.(2015). Domain-Specificity of Creativity: A study on Relationship between Visual Creativity and Visual Mental Imagery. Frontiers in Psychology, 6, Article 1870.

35. Retrieved from http://www.ncbi.nlm.nih.gov on 24/4/19.

36. Perky, C.W.(1910). An Experimental Study of Imagination. American Journal of Psychology, Vol 21 (3), 422-452.

37. Retrieved from http://www.archive.org on 26/4/19.

38. Potter,C. and Merwe,E. (2001). Spatial Ability, Visual Imagery, and Academic Performance in Engineering Graphics. Electronic publication.

39. Retrieved from http://www.researchgate.net on 24/4/19.

40. Quealey, P.A. (1980). An Experimental Study of Mental Imagery. Electronic Theses, University of Adelaide, South Australia.

41. Retrieved from http://www.proquest.com on 24/4/19.

42. Rademaker,R.L. and Pearson,J. (2012). Training Visual Imagery: Improvements of Metacognition, but not Imagery Strength. Frontiers in Psychology, Vol 3, Article 224. 23-30.

43. Retrieved from http://www.frontiersin.org on 26/4/19.

44. Shephard, S. and Metzler, D. (1988) Mental Rotation: Effects of dimensionality of objects and type of task. Journal of Experimental Psychology: Human Perception and Performance, 14(1), 3-11.

45. Retrieved from http:// www. nmr.mgh.harvard.edu on 12/04/19.

46. Snodgrass, J.G. and Vanderwart, M. (1980). A Standardized set of 260 Pictures: Norms for Name Agreement, Image Agreement, Familiarity, and Visual Complexity. Journal of Experimental Psychology: Human Learning and Memory, 6(2), 174-215.

47. Retrieved from http://www.PMIT260snodgrass1980.pdf on 12/10/18.

48. Sternberg, G., Radeborg, K. and Hedman, L.R. (1995). The Picture Superiority Effect in a Cross-Modality Recognition task. Memory and Cognition, 23(4), 425-441.

49. Retrieved from http://www.proquest.com on 2/11/18

50. Thompson,W.L., Slotnick, S.D., Burrage, M.S. and Kosslyn, S.M. (2009). Two Forms of Spatial Imagery: Neuroimaging evidence. Psychological Science, 20(10),1245-1252.

51. Retrieved from http://www2.bc.edu.pdf on 24/4/19.

52. Weldon, M.S. and Roediger, H.L. (1987). Altering Retrieval Demands Reverses Picture Superiority Effect. Memory and Cognition, 15(4), 269-280.

53. Retrieved from http://www.proquest.com on 01/10/18.

\section{AUTHORS PROFILE}

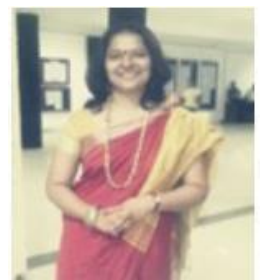

I am Ms. Suchitra Roy Chowdhury, the single author of this paper. I work as an Assistant Professor in the Dept. of Psychology at Mithibai College, Mumbai. I have a teaching experience of about 15 yrs. I have an experience of teaching psychology both for the under graduate and post graduate students. Besides that I have also taught psychology at Junior college, and other institutes like SNDT, Institute of Chemical Technology, Bachelor's of Mass Media... I am pursuing my Ph.D that aims at developing an intervention program for good life.

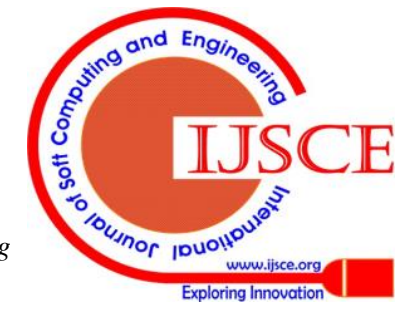

